\title{
Fertility awareness and intentions among young adults in Greece
}

\author{
Ioanna Lardou ${ }^{a}$, loannis Chatzipapas ${ }^{a}$, Michail Chouzouris ${ }^{b}$, Panos Xenos ${ }^{b}$, Nikolaos Petrogiannisc, Dimitrios Tryfosc, \\ Stephanos Chandakas ${ }^{\mathrm{d}}$, Themos Grigoriadis ${ }^{\mathrm{a}}$ and Lina Michala* \\ a1st Department of Obstetrics and Gynaecology, National and Kapodistrian University of Athens, Alexandra General Hospital, Athens, \\ Greece; bepartment of Statistics and Insurance Science, University of Piraeus, Athens, Greece; ' Naval and Veterans Hospital of Athens, \\ Athens, Greece; ${ }^{\mathrm{d} M i t e r a}$ General Hospital, Athens, Greece
}

\begin{abstract}
Background: Greece has a mean age of first motherhood at 31.5 years, higher than the European average age of 29.4. Delaying conception, however, may be an important non-reversible cause of infertility. The aim of this study was to identify possible knowledge deficits regarding fertility in young adults.

Methods: This was an online survey of young adults, regarding information on intention to parenthood and knowledge on issues affecting fertility. This study was conducted from February to December 2020, aiming for a representative sample of Greek men and women aged 18 and 26 years. The questionnaire was designed by a multidisciplinary group based on the Cardiff Fertility Knowledge Scale, which contained 22 multiple-choice or Likert-scale questions.

Results: We obtained responses from 1875 young adults, whose mean age was 22.1 years. About $91.8 \%$ of men and $94.0 \%$ of women declared an intention to have children, out of which $44.0 \%$ wanted to have two and $29.0 \%$ three children. About 52.0 and $50.8 \%$ men and women, respectively, aimed to start a family between 31 and 35 years. Residents of rural areas and those with a lower education level more likely aimed to have children before the age of 30 . The most prevalent answers for age of ideal parenthood were between 26 and 30 years for a woman and 31-35 years for a man. Smoking, alcohol consumption and sexually transmitted infections were identified as factors affecting both female and male fertility. Half of men and women, respectively, overestimated general success rates of reproductive techniques.

Conclusion: The knowledge of fertility, particularly with regards to assisted reproductive techniques' success rates, may be overestimated as more young adults plan for having children after the age of 30 .
\end{abstract}

\section{ARTICLE HISTORY}

Received 20 August 2021

Revised 20 October 2021

Accepted 14 December 2021

Published 31 December 2021

\section{KEYWORDS}

Fertility awareness; assisted reproductive techniques; planned parenthood; agerelated fertility; educational programs

\section{Introduction}

According to recent data, Greece is among the countries presenting the highest rates of first childbirth among women at age 40 and over, estimated at 5.3\%, with the mean age of motherhood steadily increasing and is currently 31.5 years, while the European average age is 29.4 years (1).

The main reasons for delayed childbearing include a competitive work environment, unemployment, immigration, reduced income, increased cost of raising children and limited access to healthcare services (2). Furthermore, women may prioritize financial independence and career development over the desire for childbirth (3). Greece has an unfavourable work environment for employed parents, at least when compared with other European countries. According to the European Institute of Gender Equality, $71 \%$ of Greek women are eligible for parental leave, as opposed to the European average of $90 \%$. Restrictions particularly apply to those who are self-employed. Greek men are further underprivileged, as only $64 \%$ can obtain parental leave, compared with $88 \%$ of their European counterparts (4).
However, deferring parenthood may affect the ability to become a parent or to achieve the desired family size. Although social fertility preservation and assisted reproductive techniques (ARTs) may offer a solution, they provide by no means a guarantee. Still, the media are overwhelmed by news of celebrities and social influencers who have their children during the fifth or- sometimes sixth- decade of life (5). This information is rarely balanced by truthful recounts of the obstacles that some of these women may have faced to achieve a perceived happy outcome.

Promoting reliable information and realistic expectations regarding the reproductive ability should empower young people to make true informed choices about their future fertility, thus deciding or not to delay childbearing. A recent report on fertility awareness among medical students in three European countries showed that Greek students were relatively realistic about the prospects of fertility decline with age. This, however, may reflect the level of information that is obtained in the obstetrics and gynaecology curriculum, rather than knowledge and attitudes applicable to the general population (6). The aim 
of this study was to identify possible knowledge deficits in young adults in the general population in order to label areas of improvement in secondary education and possibly introduce public awareness strategies.

\section{Methods}

This was an online survey of fertility awareness among young men and women aged 18-26 years in Greece.

\section{Development of the questionnaire}

A multidisciplinary team, consisting of obstetricians and gynaecologists, fertility specialists, academic teachers and statisticians, discussed the aim of the study and the formulation of a questionnaire. A thorough literature search was performed to identify similar studies and questionnaires that could be used as a basis of the study. We based the questions on the Cardiff Fertility Knowledge Scale $(7,8)$, but opted for multiple choice and Likert scale questions rather than true or false options.

The final questionnaire was anonymous and comprised of 22 questions. Out of them, five questions were on demographics (age, municipality of residence, educational level and work status), four questions regarding the intention to have children, four questions regarding factors that affect male and female fertility, along with the ideal age to father or bear a child and finally nine questions regarding ART, including egg donation, egg freezing and success rates of ART, in general, and in women over the age of 40 years.

The questionnaire was piloted for brevity and clarity in a sample of 20 young adults, and final corrections were made accordingly. It was then transcribed in an electronic format via google forms platform for easier dissemination.

Cronbach's alpha coefficient for the questionnaire omitting the five questions regarding demographics- was 0.79.

\section{Ethical approval}

The study protocol received ethical approval from the scientific board of Alexandra General Hospital (Reference No. 693/02-09-2019). At the onset of the electronic form, we included information for the participant and an option to proceed to the questionnaire after checking an online consent form. The questionnaire was anonymous and did not ask for sensitive personal information.

\section{Sample size and Recruitment}

In order to achieve a representative sample of the relevant population, we calculated the minimum number of participants, so as to achieve a $95 \%$ confidence interval and a margin of error of $3 \%$. We thus aimed for a minimum sample of 1,067 (9).

An online survey was conducted for a period of 10 months from February to December 2020. Eligibility criteria were reading knowledge of Greek and age between 18 and 26 years. Data collection followed the ethical considerations and data privacy protocols while participants gave consent via an online privacy statement. In order to achieve representativeness of the Greek population, quotas were used for geographical regions. We advertised through posters that included a QR code linking to the online questionnaire. We particularly approached university students and military recruits, and generally encouraged participants to disseminate the questionnaire link to their social groups. A total of 2014 participated in the study, of which 139 were excluded because they were 27 years old or above.

\section{Statistical analysis}

Descriptive statistics were used to describe demographic variables and fertility knowledge. Categorical data were compared using chi-squared tests. T-tests were used to compare scores of knowledge depending on the gender. A $P$ value of $<0.05$ was considered to be statistically significant. We used the SPSS (version 25.0) for analysis.

\section{Results}

Our sample consisted of 1,875 participants, of which 1,133 (60.4\%) were women and 742 (39.6\%) men. Out of them, 21 (1.1\%) already had children, and their demographics are shown in Table 1. The place or residence was defined as urban when the population was over 10,000 according to the 2011 census (10).

Table 1. Demographics.

\begin{tabular}{|c|c|c|c|c|c|c|}
\hline \multirow[t]{3}{*}{ Age (mean) } & \multirow{2}{*}{\multicolumn{2}{|c|}{$\frac{\text { Men }(n=742)}{22.7}$}} & \multirow{2}{*}{\multicolumn{2}{|c|}{$\begin{array}{c}\begin{array}{c}\text { Women } \\
(n=1,133)\end{array} \\
21.7\end{array}$}} & \multirow{2}{*}{\multicolumn{2}{|c|}{$\begin{array}{c}\text { Total }(n=1,875) \\
22.1\end{array}$}} \\
\hline & & & & & & \\
\hline & $n$ & $\%$ & $n$ & $\%$ & $n$ & $\%$ \\
\hline 18 & 45 & 6.1 & 152 & 13.4 & 197 & 10.5 \\
\hline 19 & 48 & 6.5 & 137 & 12.1 & 185 & 9.9 \\
\hline 20 & 76 & 10.2 & 143 & 12.6 & 219 & 11.7 \\
\hline 21 & 54 & 7.3 & 128 & 11.3 & 182 & 9.7 \\
\hline 22 & 85 & 11.5 & 132 & 11.7 & 217 & 11.7 \\
\hline 23 & 126 & 17 & 121 & 10.7 & 247 & 13.2 \\
\hline 24 & 114 & 15.4 & 107 & 9.4 & 221 & 11.8 \\
\hline 25 & 105 & 14.2 & 110 & 9.7 & 215 & 11.5 \\
\hline 26 & 89 & 12 & 103 & 9.1 & 192 & 10.2 \\
\hline \multicolumn{7}{|l|}{ Place of residence } \\
\hline Urban & 649 & 87.5 & 1,033 & 91.2 & 1,682 & 89.7 \\
\hline Rural & 82 & 11.1 & 88 & 7.8 & 170 & 9.1 \\
\hline Abroad & 10 & 1.3 & 7 & 0.6 & 17 & 0.9 \\
\hline \multicolumn{7}{|l|}{ Education } \\
\hline $\begin{array}{l}\text { Middle school } \\
\text { graduate }\end{array}$ & 4 & 0.5 & 3 & 0.3 & 7 & 0.4 \\
\hline $\begin{array}{l}\text { High school } \\
\text { graduate }\end{array}$ & 99 & 13.3 & 126 & 11.1 & 225 & 12 \\
\hline University student & 596 & 80.3 & 970 & 85.6 & 1,566 & 83.5 \\
\hline \multicolumn{7}{|l|}{ Working status } \\
\hline Student & 362 & 48.8 & 766 & 67.6 & 1,128 & 60.2 \\
\hline Unemployed & 65 & 8.8 & 31 & 2.7 & 96 & 5.1 \\
\hline $\begin{array}{l}\text { Employed (full or } \\
\text { part time) }\end{array}$ & 291 & 39.2 & 285 & 25.2 & 576 & 30.7 \\
\hline
\end{tabular}




\section{Intention of having children}

About $91.8 \%$ of men and $94.0 \%$ of women revealed that they want to have children in the future, and out of them, $120(6.4 \%)$ would want to have one, 821 (43.8\%) two, 375 (20.0\%) three and $126(6.7 \%)$ more than three children. There was no statistical difference between men and women in their intention.

Subsequently, when asked about the likely age they would have children, 52.0 and $50.8 \%$ of men and women, respectively, aimed to have children between 31 and 35 years. Those who wanted to have more than three children planned to have them before the age of 30. However, there were 224 participants $(11.9 \%)$, of which 118 women, who wished to have three or more children after the age of 30 .

When comparing participants according to place of residence, those residing in a rural area were more likely to aim to have children before the age of 30 than those residing in urban centres ( 48.0 vs $40.0 \%, P=0.014$ ). Similarly, secondary school graduates were statistically significantly more likely to want to have children under the age of 30 , in comparison with university students or graduates (53.2 vs $37.9 \%, P<0.001)$. There was no statistically significant difference in the number of children planned, depending on the place of residence or education level.

\section{Knowledge on fertility and comparison to age of planned parenthood}

Next, participants were asked about the ideal age to have children, where the most prevalent answers were between 26 and 30 years for a woman (60.0\%) and 31-35 years for a man (47.0\%). Slightly more men than women agreed that the ideal age for a woman to have children is between 26 and 30 years of age (460- $61.3 \%$, vs $698-59.5 \%$ respectively). However, $41.2 \%$ of women (484) were seeing themselves likely to have children in this age margin, and $56.0 \%$ were more likely to have children after the age of 30 (Figure 1).

Following on, participants were asked to rate factors that affect the fertility of men and women, the results of which are listed in Tables 2 and 3.

\section{Knowledge on ART}

With regards to ART success rates, 24.0 and $30.0 \%$ of men and women, respectively, correctly approximated general ART cycle success rates at $30 \%$ (11). Nevertheless, 48.0 and $43.0 \%$ of men and women, respectively, overestimated general success rates, with 214 answering that this would amount to $90 \%$. When asked about ART success rates per cycle in women over 40 years of age, $41.0 \%$ of men and $37.0 \%$ of women overestimated them to be over $30 \%$, whereas $41.0 \%$ and $44.0 \%$ of men and women, respectively, correctly identified them to be in the $10-20 \%$ range.

Finally, 32.9\% of women would consider egg freezing and $25.3 \%$ of men would recommend this to their partner. For the remainder, the most important reason for avoiding it was mostly the cost for women and a preference for natural conception for men. The results of the Likert scale are shown in Tables 4 and 5 .

\section{Discussion}

This study focuses primarily on exploring tendencies and perceptions of young people in Greece in relation to reproductive health knowledge and assisted reproduction. We decided on an internet-based survey, as it is a convenient and effective way of reaching large numbers of younger participants, who in their majority will be computer native.

A sample size of 1,875 was well above our initial recruitment intention. We can thus draw important, generalizable conclusions. Young men remained relatively underrepresented in the sample. This is often the case in surveys where female responders may be more willing to participate $(12,13)$. Still, the number of men included in the study was deemed adequate.

With regards to intention to have children, participants overwhelmingly stated they wanted to have offsprings in the future, with almost half of them hoping to have two. Almost $27 \%$ stated that they would consider having three or more children. About half were thinking that they were more likely to start a family between the ages of 31 and 35 years. This was similar for both men and women, with $11.4 \%$ of women planning to have at least three children despite starting a family after the age of 30. This may demonstrate an overoptimistic approach on their ability to carry a pregnancy when into their late 30 s or 40 s.

About $5 \%$ of women and $10 \%$ of men were seeing themselves having children after the age of 36 years and a very small minority after the age of 40 . Again, this proportion of young people may not be fully aware of age-related fertility decline. Still, this proportion was much lower than what was seen in a similar survey in the UK and Denmark, where nearly one-fifth of the women and one-third of the men desired a first child at or after 35 years (14).

Despite their intentions, about $60.0 \%$ of respondents in this study correctly acknowledged the ideal age of childbearing for a woman to be under 30 years. Age was also identified as a significant factor affecting female fertility by both men and women, with only 4.0 and $5.0 \%$ of men and women, respectively, stating that they either did not know or felt that age had any effect on fertility.

Smoking and alcohol consumption along with obesity were all identified as potentially detrimental factors for female and male fertility. Similarly, history of sexually transmitted infections (STIs) or previous abortions were considered to play a significant role in male and female fertility. It is, however, notable that prior use of condoms was among the least stated factors affecting either male or female fertility. Usage of condoms prevents STIs, and as such, we expected it to be identified as an important factor interfering with future fertility. It may, however, be that respondents did not fully appreciate the reasoning of the question. In future questionnaires, we could consider incorporating an explanatory sentence on this or adding further questioning on alternative ways to prevent STI transmission, 

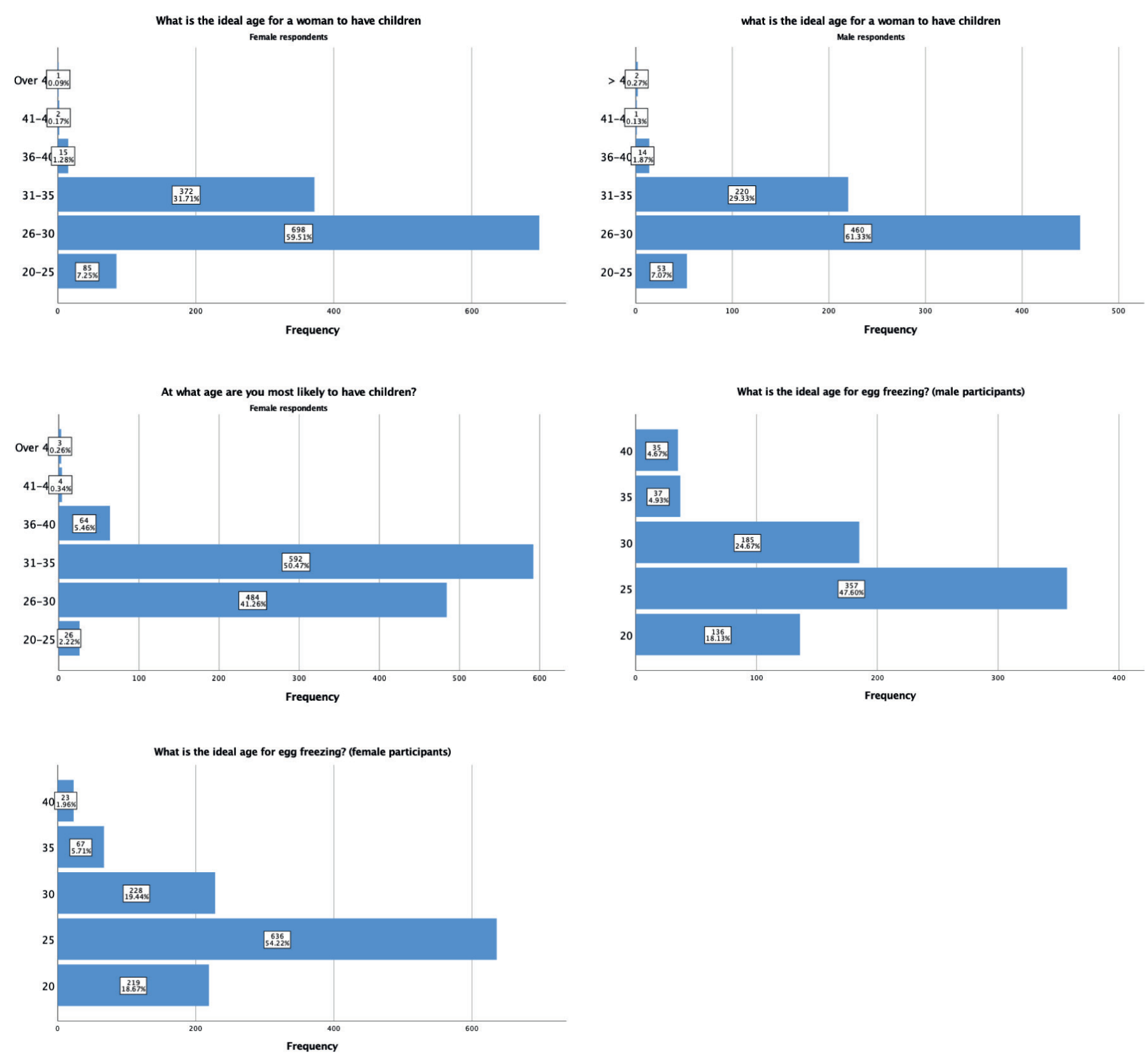

Figure 1. Fertility.

Table 2. Men's knowledge on factors affecting female fertility.

\begin{tabular}{|c|c|c|c|c|c|c|c|c|}
\hline & $\begin{array}{l}\text { Not at } \\
\text { all (\%) }\end{array}$ & 2 (\%) & $3(\%)$ & $4(\%)$ & $5(\%)$ & $6(\%)$ & $\begin{array}{c}\text { Very } \\
\text { significantly } \\
(\%)\end{array}$ & $\begin{array}{c}\text { I don't } \\
\text { know (\%) }\end{array}$ \\
\hline Smoking & 2.4 & 7.5 & 8.5 & 13.3 & 18.8 & 11.5 & 35.9 & 2.1 \\
\hline Daily consumption of alcohol & 1.3 & 5.3 & 5.1 & 10.7 & 16.7 & 14.9 & 44.1 & 1.9 \\
\hline Not using condoms in the past & 13.9 & 8.0 & 10.0 & 10.7 & 15.3 & 12.5 & 19.3 & 10.3 \\
\hline Previous usage of the $\mathrm{COC}^{\mathrm{a}}$ & 5.6 & 9.7 & 9.9 & 15.2 & 18.1 & 12.5 & 19.1 & 9.9 \\
\hline Previous abortion(s) & 1.7 & 6.1 & 4.4 & 8.9 & 16.8 & 19.7 & 36.8 & 5.5 \\
\hline Age & 2.4 & 6.4 & 4.0 & 8.7 & 17.9 & 21.9 & 36.9 & 1.9 \\
\hline
\end{tabular}

a, COC: combined oral contraceptives. 
Table 3. Women's knowledge on factors affecting female fertility.

\begin{tabular}{|c|c|c|c|c|c|c|c|c|}
\hline & $\begin{array}{l}\text { Not at } \\
\text { all (\%) }\end{array}$ & $2(\%)$ & $3(\%)$ & $4(\%)$ & $5(\%)$ & $6(\%)$ & $\begin{array}{c}\text { Very } \\
\text { Significantly } \\
(\%)\end{array}$ & $\begin{array}{c}\text { I don't } \\
\text { know (\%) }\end{array}$ \\
\hline Smoking & 1.0 & 13.2 & 9.8 & 12.3 & 14.0 & 8.2 & 35.0 & 6.5 \\
\hline Daily usage of alcohol & 0.7 & 10.0 & 6.8 & 9.3 & 11.5 & 12.4 & 44.9 & 4.3 \\
\hline Not using condoms in the past & 25.9 & 10.2 & 6.7 & 9.4 & 9.0 & 5.6 & 11.1 & 22.1 \\
\hline Previous usage of the $\mathrm{COC}^{\mathrm{a}}$ & 13.5 & 17.4 & 13.6 & 10.9 & 9.5 & 5.5 & 9.0 & 20.6 \\
\hline Previous abortion(s) & 3.0 & 12.2 & 9.6 & 11.7 & 12.4 & 14.9 & 28.1 & 8.0 \\
\hline Age & 2.6 & 9.6 & 8.1 & 12.4 & 16.5 & 17.1 & 30.9 & 2.7 \\
\hline
\end{tabular}

a, COC: combined oral contraceptives

b, STIs: sexually transmitted infections.

Table 4. Reasons to avoid egg freezing (male participants).

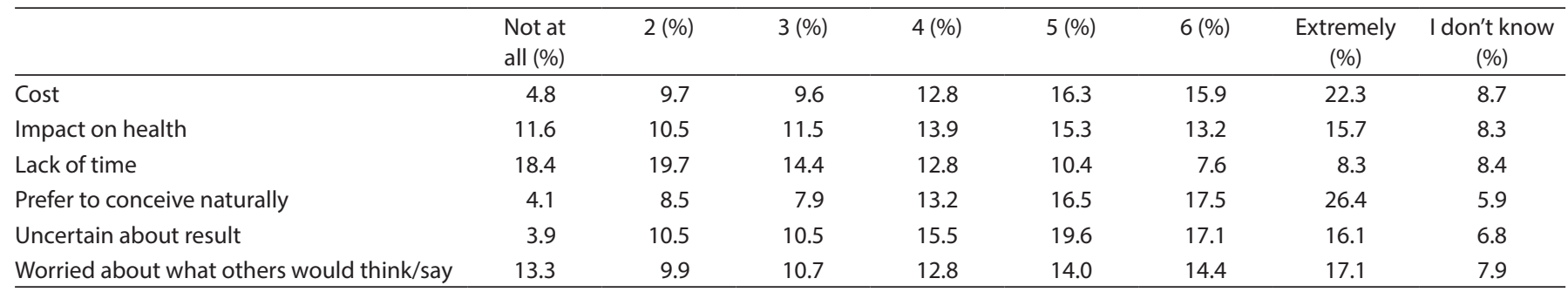

Table 5. Reasons to avoid egg freezing (women participants).

\begin{tabular}{|c|c|c|c|c|c|c|c|c|}
\hline & Not at all (\%) & $2(\%)$ & $3(\%)$ & $4(\%)$ & $5(\%)$ & $6(\%)$ & $\begin{array}{c}\text { Extremely } \\
\text { (\%) }\end{array}$ & $\begin{array}{c}\text { I don't know } \\
(\%)\end{array}$ \\
\hline Cost & 1.4 & 7.8 & 8.6 & 11.0 & 15.3 & 11.9 & 32.0 & 11.9 \\
\hline Impact on health & 12.7 & 11.0 & 9.2 & 11.8 & 13.2 & 9.7 & 19.1 & 13.2 \\
\hline Lack of time & 24.1 & 21.0 & 14.4 & 11.5 & 8.3 & 3.6 & 4.7 & 12.4 \\
\hline Prefer to conceive naturally & 3.5 & 9.7 & 8.7 & 11.0 & 15.4 & 15.1 & 29.2 & 7.3 \\
\hline Unsure of result & 3.2 & 10.1 & 13.1 & 15.1 & 17.0 & 15.7 & 18.3 & 7.5 \\
\hline
\end{tabular}

such as frequent testing for highly prevalent STIs or having longterm, stable sexual relationships.

According to similar studies from other parts of the world, fertility awareness tends to be low to moderate $(15,16)$ irrespective of gender (17). Men, in particular, appear to have significant gaps in their knowledge of factors affecting their fertility, although they were more aware of modifiable risk factors, such as STIs and smoking cigarettes, as opposed to fixed and health-related factors, such as delayed puberty, diabetes and cardiovascular disease (18).

With regards to egg freezing, about half of participants correctly stated that this should ideally take place prior to 30 years of age. However, only about one-third had a clear positive attitude towards this. With fertility declining with age and women favouring career over childbearing, social egg freezing is an appealing option for fertility preservation. More women are storing their oocytes to maintain the potential to have a baby in the future. However, they tend to proceed to egg freezing when they are already in their later 30s when the success rates of the method are limited (19). Furthermore, younger women are disadvantaged by the current legislated limit of 10 years' duration of storage (20).

In this study, the main barrier to social egg freezing was cost. A proportion of participants also mentioned that they would prefer natural methods of conception or that they were uncertain about results. This proportion was similar to the number of undecided participants regarding the recourse to reproductive fertility methods, in general. Lack of time had the least impact on their decision to future egg freezing.

With regards to ART cycle success rates, about one-third of participants correctly appreciated this to be in the range of 30\% (11). Furthermore, almost half accurately recognized reduced success rates per ART cycle in women over the age of 40 (21). The remainder, however, tended to be overoptimistic about the ability of ART to overcome infertility. Likewise, past studies of highly educated young adults in Europe and America found that they were not sufficiently aware of age-related female infertility 
and falsely believed that ART will overcome any fertility problems, even those associated with age (22-25). Similar results were found in a study of Chinese university students (13).

The majority of participants were living in urban centres, which is typical of the current demographic distribution in the country (24) and, as expected, only $1 \%$ of participants stated that they already had children (25). Nevertheless, there were limitations, in that eight out of 10 participants (83.5\%) were students or university graduates, a proportion that is higher than what is typical for young Greeks (26). Also, less number of participants were unemployed (27), possibly due to the fact that they were defining themselves as students. It is possible, therefore, that participants favoured career over family, more so than in the general population of young adults, and this may explain a tendency to postpone parenthood after professional goals have been fulfilled. However, a higher level of education would also suggest more opportunities for exposure to information regarding reproductive health, and this indicates a likely failing in the education system. Fertility education should be part of the core curriculum in schools in order to ensure children and young people have a good foundation on reproductive health and choices.

Several countries have already introduced relevant educational programmes. For example, the British Fertility Society, in partnership with the Royal College of Obstetricians and Gynaecologists, other learned societies and non-profit institutions introduced the 'Fertility Education Initiative', aiming at providing accurate information about fertility at schools and promoting fertility awareness (28). On a similar note, the Center for Disease Control introduced the 'Reproductive Life Plan (RLP)' to promote preconceptional health for those intending to have children in the future (29). Finally, the Australian government has funded a public education programme named 'Your Fertility', aiming to improve knowledge among health professionals and the public (30). The project has also focused on introducing teaching resources for primary and secondary schools, with supporting online learning tools for teachers, including an e-learning module and class handout material (31).

Social media and internet websites can also influence and inform the public about infertility (5), as shown by the study that assesses an evidence-based website on RLP called 'reproduktivlivsplan.se' (32). However, many accounts currently available are created by patient groups or the private sector, and thus, may provide skewed, non-evidence-based information. Hopefully, more learned societies will create social media accounts in the future in order to provide accurate, yet approachable material. We would also expect relevant societies in Greece to provide healthcare providers with materials to help young people form reproductive goals, improve future fertility or advice on fertility preservation, following the successful example of the Swedish RLP model (33).

In conclusion, the results of this project provide a snapshot of what are the current knowledge and intentions of young men and women in Greece regarding childbearing and fertility. Although there are intentions for childbearing before the age of 30 , and despite adequate understanding of the limitations of ART on improving fertility, there are still a significant proportion of young adults who lack the necessary information about factors leading to declining fertility. Although social and financial reasons may be at the heart of postponed motherhood, improving fertility awareness through specific educational programmes can provide with the necessary knowledge to make informed decisions about deferring or not childbearing.

With this in mind, we suggest the introduction of relevant educational programmes for the general public, including the incorporation of fertility awareness in the sexual and relations education curriculum, following the Australian and Swedish paradigm.

\section{Acknowledgements}

The authors are grateful to the staff of Alexandra General Hospital and the Naval and Veterans Hospital of Athens. They also thank HOPEgenesis, a non-profitable organisation aiming at improving low birth rates in Greece, for their support and encouragement.

\section{Disclosure statement}

The authors have no conflict of interest to declare.

\section{Funding}

The authors received no funding for their work in this study.

\section{Notes on Contributors}

loanna Lardou, MD. Obstetrician and Gynaecologist, PhD student, 1st Department of Obstetrics and Gynaecology.

loannis Chatzipapas, MD, PhD. Constultant Obstetrician and Gynaecologist, 1st Department of Obstetrics and Gynaecology.

Michail Chouzouris, Statistician/Data Analyst, Public Economics, PhD Candidate, Department of Statistics and Insurance Science, University of Piraeus.

Panos Xenos, PhD. Assistant Professor of Statistics and Insurance Science, University of Piraeus.

Nikolaos Petrogiannis, MD, MSc, PhD. Obstetrician and Gynaecologist, Captain, Director of the IVF Unit, Naval and Veterans Hospital of Athens.

Dimitrios Tryfos, MD, MSc. Obstetrician and Gynaecologist, Captain, Director of the IVF Unit, Naval and Veterans Hospital of Athens.

Stephanos Chandakas, MD, MBA, PhD. Consultant GynaecologistReproductive Surgeon Chairman, BOD, Mitera Hospital, Athens, Greece.

Themos Grigoriadis, MD, PhD. Assistant Professor in Obstetrics and Gynaecology- Urogynaecology, 1st Department of Obstetrics and Gynaecology. 
Lina Michala, PhD, FRCOG. Assistant Professor in Obstetrics and Gynaecology- Paediatric and Adolescent Gynaecology, 1st Department of Obstetrics and Gynaecology.

\section{ORCID}

loannis Chatzipapas (1) https://orcid.org/0000-0002-7801-597X Themos Grigoriadis (1) https://orcid.org/0000-0002-4301-8775 Lina Michala (1) https://orcid.org/0000-0001-8629-9776

\section{References}

1. Eurostat. Women in the EU are having their first child later. 2021. Available from: https://ec.europa.eu/eurostat/web/products-eurostatnews/-/ddn-20210224-1 [cited 21 May 2021].

2. Mills $M$, Rindfuss RR, McDonald P, Te Velde E. Why do people postpone parenthood? Reasons and social policy incentives. Hum Reprod Update. 2011;17:848-60. doi: 10.1093/humupd/dmr026

3. Blossfeld H-P, Huinink J. Human capital investments or norms of role transition? How women's schooling and career affect the process of family formation. Am J Sociol. 1991;97:143-68. doi: 10.1086/229743

4. European Institue for Gender Equality (EIGE). Who is eligible for parental leave in the EU-28? Vilnius: Publ Off Eur Union; 2021.

5. Blakemore JK, Bayer AH, Smith MB, Grifo JA. Infertility influencers: an analysis of information and influence in the fertility webspace. J Assist Reprod Genet. 2020;37:1371-8. doi: 10.1007/s10815-020-01799-2

6. Delbaere I, Pitsillos T, Tydén T, Kerckhof L, lliadis SI. Fertility awareness and parenthood intentions among medical students in three European countries. Eur J Contracept Reprod Heal Care Off J Eur Soc Contracept. 2021;26(4):312-322. doi: 10.1080/13625187.2021.1901877

7. Maeda E, Boivin J, Toyokawa S, Murata K, Saito H. Two-year follow-up of a randomized controlled trial: knowledge and reproductive outcome after online fertility education. Hum Reprod. 2018;33:2035-42. doi: 10.1093/humrep/dey293

8. Zhou Y, Luo Y, Wang T, Cui Y, Chen M, Fu J. College students responding to the Chinese version of Cardiff fertility knowledge scale show deficiencies in their awareness: a cross-sectional survey in Hunan, China. BMC Public Health. 2020;20:810. doi: 10.1186/s12889-020-08937-6

9. Desu MM, Raghavarao $D$, editors. Statistical modeling and decision science. In: Sample size methodology. Boston, MA: Academic Press; 1990, pp. 63-73.

10. HSA, Hellenic Statistical Authority. Census 2011. Available from: https:// www.statistics.gr/en/2011-census-pop-hous [cited 21 May 2021].

11. Centers for Disease Control and Prevention. 2018 ART fertility clinic success rates report. Atlanta, GA; 2020. Available from: https:// www.cdc.gov/art/pdf/2018-report/ART-2018-Clinic-Report-Full.pdf [cited 15 October 2021].

12. Lampic C, Svanberg AS, Karlström P, Tydén T. Fertility awareness, intentions concerning childbearing, and attitudes towards parenthood among female and male academics. Hum Reprod. 2006;21:558-64. doi: 10.1093/humrep/dei367

13. Chan CHY, Chan THY, Peterson BD, Lampic C, Tam MYJ. Intentions and attitudes towards parenthood and fertility awareness among Chinese university students in Hong Kong: a comparison with Western samples. Hum Reprod. 2015;30:364-72. doi: 10.1093/humrep/deu324

14. Vassard D, Lallemant C, Nyboe Andersen A, Macklon N, Schmidt L. A population-based survey on family intentions and fertility awareness in women and men in the United Kingdom and Denmark. Ups J Med Sci. 2016;121:244-51. doi: 10.1080/03009734.2016.1194503

15. Hammarberg K, Setter T, Norman RJ, Holden CA, Michelmore J, Johnson L. Knowledge about factors that influence fertility among Australians of reproductive age: a population-based survey. Fertil Steril. 2013;99:502-7. doi: 10.1016/j.fertnstert.2012.10.031

16. Pedro J, Brandão T, Schmidt L, Costa ME, Martins MV. What do people know about fertility? A systematic review on fertility awareness and its associated factors. Ups J Med Sci. 2018;123:71-81. doi: 10.1080/03009734.2018.1480186

17. Nouri K, Huber D, Walch K, Promberger R, Buerkle B, Ott J, et al. Fertility awareness among medical and non-medical students: a case-control study. Reprod Biol Endocrinol. 2014;12:94. doi: 10.1186/1477-7827-12-94

18. Daumler D, Chan P, Lo KC, Takefman J, Zelkowitz P. Men's knowledge of their own fertility: a population-based survey examining the awareness of factors that are associated with male infertility. Hum Reprod. 2016;31:2781-90. doi: 10.1093/humrep/dew265

19. Mertes $H$, Pennings $G$. Social egg freezing: for better, not for worse. Reprod Biomed Online. 2011;23:824-9. doi: 10.1016/j. rbmo.2011.09.010

20. Anderson RA, Davies MC, Lavery SA. Elective egg freezing for non-medical reasons: scientific impact paper no. 63. BJOG. 2020;127:e113-21. doi: 10.1111/1471-0528.16025

21. Devesa M, Tur R, Rodríguez I, Coroleu B, Martínez F, Polyzos NP. Cumulative live birth rates and number of oocytes retrieved in women of advanced age. A single centre analysis including 4500 women $\geq 38$ years old. Hum Reprod. 2018;33:2010-7. doi: 10.1093/humrep/dey295

22. Deatsman S, Vasilopoulos T, Rhoton-Vlasak A. Age and fertility: a study on patient awareness. JBRA Assist Reprod. 2016;20:99-106. doi: 10.5935/1518-0557.20160024

23. Nakagawa HM. Fertility awareness campaign. JBRA Assist Reprod. 2018;22:284-5. doi: 10.5935/1518-0557.20180074

24. Statista. Greece: degree of urbanization from 2009 to 2019 . Available from: https://www.statista.com/statistics/276402/urbanization-in-greece/ [cited 21 May 2021].

25. HSA (Hellenic Statistical Authority). Births, 2019. Available from: https://www.statistics.gr/en/statistics/-/publication/SPO03/- [cited 21 May 2021].

26. Eurostat. Population by educational attainment level, sex and age (\%) - main indicators. Available from: https://ec.europa.eu/eurostat/ databrowser/view/EDAT_LFSE_03__custom_983324/settings_1/ table?lang=en [cited 22 May 2021].

27. Statista. Greece: youth unemployment rate from 1999 to 2020. Available from: https://www.statista.com/statistics/812053/youth-unemployment-rate-in-greece/ [cited 21 May 2021].

28. BFI, British Fertility Society. A guide to fertility. 2016. Available from: https://www.britishfertilitysociety.org.uk/fei/ [cited 25 May 2021].

29. Robbins CL, Gavin L, Carter MW, Moskosky SB. The link between reproductive life plan assessment and provision of preconception care at publicly funded health centers. Perspect Sex Reprod Health. 2017:49:167-72. doi: 10.1363/psrh.12030

30. Hammarberg K, Norman RJ, Robertson S, McLachlan R, Michelmore J, Johnson L. Development of a health promotion programme to improve awareness of factors that affect fertility, and evaluation of its reach in the first 5 years. Reprod Biomed Soc. 2017;4:33-40. doi: 10.1016/j. rbms.2017.06.002

31. Family Planning Victoria. Fertility and assisted reproduction: teaching module. 2019. Available from: https://www.fpv.org.au/ blog/fertility-and-assisted-reproduction-teaching-module [cited 10 October 2021].

32. Ekstrand Ragnar M, Niemeyer Hultstrand J, Tydén T, Larsson M. Development of an evidence-based website on preconception health. Ups J Med Sci. 2018;123:116-22. doi: 10.1080/03009734.2018.1476423

33. Koo Andersson M, Tydén T. Implementation of reproductive life planning (RLP) in primary health care supported by an evidence-based website. Eur J Contracept Reprod Heal Care. 2020;25:1-7. doi: 10.1080/13625187.2019.1695117 